\title{
A CONSTRUÇÃo DA IDENTIDAde de SUJEITOS DEFICIENTES NO GRUPO TERAPÊUTICO-FONOAUDIOLÓGICO ${ }^{1}$
}

\author{
IDENTITY FORMATION OF DISABLED INDIVIDUALS WITHIN A SPEECH THERAPY
}

GROUP

\author{
Gabriela Almeida LEITE2 \\ Maria Inês Bacellar MONTEIRO3
}

\begin{abstract}
RESU M O: nesteestudo, consideramos queo sujeito se constitui à medida que suas ações vão sendo interpretadas pelo outro, através da internalização de papéis, definidos, inicialmente, pelas pessoas que são referência mais concreta da criança, como a família e, posteriormente, pelo grupo social maior do qual ela faz parte. Nosso objetivo foi refletir sobre a formação/ construção da identidade de jovens deficientes mentais que partici pavam de atendimento fonoaudiológico, realizado em grupo, analisando o papel da linguagem no processo de construção da imagem que o sujeito faz de si mesmo. O estudo teve sua origem a partir dos resultados obtidos em pesquisas realizadas anteriormente, com grupos de irmãos de sujeitos considerados deficientes mentais. Esses resultados revelaram a imagem negativa que os irmãos têm em relação ao irmão deficiente. $O$ material analisado faz parte de um banco de dados de dois anos de filmagens das interações de jovens deficientes no grupo terapêutico-fonoaudiológico de uma clínica-escola. Os dados foram transcritos e analisados segundo diretrizes da análise microgenética considerando as minúcias dos acontecimentos, os detalhes e o recorte de episódios interativos, sendo o exame orientado para o funcionamento dos sujeitos, as relações intersubjetivas e as condições sociais da situação. As análises realizadas procuraram relacionar a imagem que esses sujeitos têm de si com a imagem transmitida pelo grupo social do qual eles fazem parte. Os resultados mostraram a ressonância do discurso do grupo social nos dizeres dos sujeitos. Concluímos que para transformar a imagem que os sujeitos deficientes mentais têm de si mesmos, precisamos ações que incidam sobre aqueles que os rodeiam, ou seja, a família, os amigos, os colegas e o grupo social em geral.
\end{abstract}

PALAVRAS-CHAVE: constituição da subjetividade; deficiência mental; grupo de jovens; educação especial.

\begin{abstract}
: in this study, we consider the personality of our subjects as being shaped by means of their actions being interpreted by others. This happens via the internalization of roles. These roles are defined, in the first instance, by those persons who provide the most concrete reference points for the child, in particular their family, and beyond that by the wider social group to which they belong. Our objective was to reflect upon the formation of the personal identity of mentally disabled young people who were receiving speech therapy, this therapy being conducted in a group context. Transcripts of the language used by the subjects in constructing their self image were analyzed. This study was based upon the results obtained from previous research, conducted with groups of siblings of subjects classified as mentally disabled. These results revealed a negative image held by those siblings of their disabled brother or sister. The material analyzed is part of a data bank of videotapes, of disabled youngsters receiving group speech therapy in a school clinic setting, taken over a two year period. This data was transcribed and analyzed according to the guidelines of micro genetic analysis, taking into consideration minute details of interviews and in particular details and clips of interactive episodes. The examination of the data was directed towards the actions of the subjects of the study, their interpersonal relations and the social context in which these took place. The analysis conducted in this study aims to establish a relationship between the images these subjects have of themselves and the image put across by the social group to which they belong. The results demonstrated the resonance of the discourse of the social group in the verbalizations of the subjects. We conclude that to transform the image that the subjects with intellectual disability have of themselves it is necessary to direct actions to those who are close to them, namely family, friends, colleagues and their social group in general.
\end{abstract}

KEYWORDS: formation of subjectivity; mental disability; groups of young people; special education.

\footnotetext{
${ }^{1}$ A poio Financeiro: CN Pq (Programa PIBIC Iniciação Científica)

${ }^{2}$ Graduada em Fonoaudiologia, Universidade M etodista de Piracicaba, Curso de Fonoaudiologia gabyalmeida.fono@hotmail.com

${ }^{3}$ Doutora, Universidade M etodista de Piracicaba, Programa de Pós-Graduação em Educação mbmontei@unimep.br
} 


\section{INTRODUÇÃO}

Nesteestudo, partimos do pressuposto que o sujeito vai seconstituir à medida quesuas ações vão sendo interpretadas pel o outro através da internal ização de papéis, definidos, inicialmente, pelas pessoas que são referência mais concreta da criança, como a família e, posteriormente, pel o grupo social maior no qual está inserida.

Assim, consideramos queo sujeito deficientemental formará a imagem de si mesmo a partir de como os "outros" o significam.

Alguns pesquisadores já apontaram para a importância das interações sociais na formação dos sujeitos e destacaram as impli cações das interpretações do grupo social na constituição do sujeito deficiente mental. Encontramos nesses trabal hos apoio para realizar uma reflexão inicial a que nos propusemos neste estudo, ou seja, conhecer de que maneira as interações travadas no interior do grupo fonoaudiológico poderiam contribuir para a formação da identidade dos jovens participantes.

Glat (1989), por exemplo, afirma que os sujeitos vão configurando as suas respectivas identidades a partir das percepções e representações dos queestão a sua volta. N estesentido, conclui-se quea imagem quea pessoa deficienteconstrói de si mesma reflete a visão de seus parceiros sociais.

Lima, Maia eDistler (1999) acrescentam a essa idéia, o fato de quesendo a família o núcleo social básico, as relações aí estabelecidas irão depender das relações interpessoais de seus integrantes. Assim, as experiências da vida familiar podem auxiliar ou dificultar o processo de desenvolvimento de seus membros. Em outras palavras, o quea pessoa édepende de como são estabel ecidas as relações familiares (LIMA; MAIA; DISTLER, 1999, p. 37).

Podemos afirmar, ainda, queéna ecom a família quea criança adquire a linguagem e com ela os valores socioculturais. Portanto, é nesse grupo que ela iniciará a construção das bases para o relacionamento social .

Além disso, é necessário considerar que os valores culturais, transmitidos pelo grupo familiar, refletem os valores do grupo social maior em que a família está inserida.

Seguindo essa linha de raciocínio, devemos refletir sobre as influências da família e do grupo social na formação/ constituição de pessoas que apresentam características que fogem ao padrão comum dos demais sujeitos que compõem essegrupo.

Partindo do pressuposto queéa sociedade que estabelece as regras ou padrões dos atributos físi cos e comportamentais considerados "normais", podemos deduzir que os indivíduos que se desviam dessa norma serão rotulados de "anormais" e, conseqüentemente, serão estigmatizados. O conceito denormalidade é, portanto, determinado pelas exigências de cada momento histórico; assim, os 
critérios de desvio, excepcionalidade, ou deficiência, estão sempre relacionados ao contexto social. Considerando que o sujeito vai se constituir a partir das interpretações de suas ações pelo grupo social no qual está inserido, podemos concluir quea visão do sujeito a respeito de si mesmo dependerá dos valores eda época em que vive.

O grupo social vai expressar suas crenças e valores através da linguagem. Esta, por sua vez, é um fator relevante para o desenvolvimento mental da criança, tem um papel social importante e exerce uma função organizadora e planejadora de seu pensamento.

Esta idéia foi amplamente discutida por importantes pesquisadores, tais como $V$ ygotsky e Bakhtin. Suas pesqui sas revelam queéatravés da linguagem que a criança entra em contato com o conhecimento humano e adquiri conceitos sobre o mund o quea rodeia, apropriando-se da experiência acumulada pelo gênero humano no decurso da história social. Assim, éa partir da interação social, da qual a linguagem é expressão fundamental, que a criança constrói a própria individualidade.

A presença do grupo social ou do "outro" aparece, portanto, desde cedo, como uma realidade cujo objetivo é ajustar ou normalizar o indivíduo. Os sujeitos que apresentam padrões diferentes daqueles comuns à mai oria do grupo geralmente não conseguem encontrar identificação com os demais sujeitos do grupo.

Pessoas rotuladas como deficientes mentais podem seapresentar mais dependentes e incapacitadas, do que seria resultante de sua condição orgânica, por terem aprendido a desempenhar o papel dedeficientes. Como esses indivíduos são geralmente assim rotulados, logo após seu nascimento ou nos primeiros anos devida, acabam socializados em uma situação de desvantagem - enquanto pessoas estigmatizadas. Isso afeta sua identidade pessoal, aumentando a probabilidade de assumirem o papel que lhes é atribuído.

Diversos autores, embora não neguem a existência defatores orgânicos predeterminantes, postulam quea deficiência é antes de mais nada um fenômeno social.

N essa perspectiva, a deficiência não deve ser vista somente como uma característica intrínseca do indivíduo, pois, afinal, uma pessoa só é deficiente se assim for considerada pelos demais. Torna-se importante, portanto, analisar como se dá a relação entre pessoas "deficientes" e as "normais".

Segundo Lopes (2002), duranteséculos, a noção de pessoa permaneceu estruturalmente a mesma: uma pessoa integrada em sua dualidade de corpo e alma, consciência e ação.

Esse autor destaca que a concepção de sujeito vai se diferenciando das concepções de indivíduo passando a engl obar a realidade histórica. 
Segundo Fromm (1977), apesar da personalidade tender a seconformar às definições culturais e regras sociais, sua diversidade se dá em função da complexidade dessas definições e regras. Para ele, à medida que as sociedades tornam-se mais complexas, os indivíduos, embora semelhantes, são cada vez mais originais na maneira específica por que solucionam seu problema humano.

As mudanças, ao longo da história, na concepção de sujeito, têm implicações importantes quando consi deramos quea maneira como um indivíduo vê a si mesmo e se situa no mundo depende, fundamentalmente, da mensagem que ele recebe das pessoas com as quais convive. Ou, segundo Goffman (1982), a identidade pessoal e social é uma função dos interesses e definições que os outros têm em relação a ele. A identidade pessoal é determinada essencialmente pelo papel que ocupamos no mundo e pelo modo como somos percebidos e tratados pelos demais.

Como esse lugar que ocupamos muda, dependendo do momento edo período de desenvolvimento pelo qual o sujeito está passando, a construção da identidade tem um caráter dinâmico deconstantetransformação. Segundo Silvares (2003), a construção da identidade pessoal é consi derada a tarefa mais importante da adolescência, o passo crucial da transformação do adolescente em adulto produtivo e maduro.

Para Erikson (1972), construir uma identidade implica em definir quem a pessoa é, quais são seus valores e quais as direções que deseja seguir pela vida. Para ele, o termo identidade pode ser entendido como a concepção de si mesmo, composta de valores, crenças e metas com as quais o indivíduo está solidamente comprometido. O autor afirma que é obrigação das gerações mais vel has transmitirem valores sólidos, sobre os quais os mais novos irão construir sua identidade.

Kimmel eWeiner (1998) afirmam que quanto mais desenvolvido for o sentimento de identidade, mais o indivíduo valoriza o modo como é parecido ou diferente dos demais, e mais claramente reconhece suas limitações e habilidades. Quanto menos desenvolvida está a identidade, mais o indivíduo necessita do apoio deopiniões externas para seaval iar, ecompreendemenos as pessoas como distintas.

Como vimos em todos os estudos citados, a interpretação que o grupo faz do sujeito é muito importante para a leitura que este fará de si mesmo e para sua constituição. Sea sociedadetiver concepções negativas dos deficientes, ou não conseguir interpretar suas ações como significativas, esses sujei tos vão se constituir a partir dessa imagem, e suas ações retratarão essa visão.

$\mathrm{Na}$ clínica fonoaudiológica, temos a linguagem como meta central e precisamos considerar como esta está colaborando para a constituição de sujeitos mais felizes, mais integrados no seu grupo social emais maduros. Nestesentido, é necessário conhecermos como o grupo, constituído pelos sujeitos deficientes e terapeutas/ estagiários, está colaborando nessa direção. 
Considerando-se a linguagem como uma atividade constitutiva do sujeito, procurou-se, aqui, avaliar o seu papel na construção da identidade dos sujeitos, relacionando as marcas do grupo social e a formação da significação desi mesmo.

\section{Método}

O estudo foi realizado numa perspectiva teórico-metodológica histórico-cultural, uma vez que esta permite a compreensão do processo social de constituição do sujeito possibilitado pela linguagem. Trata-se, portanto, conforme denominado por Freitas (2003), de uma pesquisa qualitativa de orientação sóciohistórica.

A situação de estudo, grupo de adolescentes deficientes em atendimento fonoaudiológico, não foi criada especificamente para fins derealização da pesquisa, pois faz parte de uma prática comum da clínica-escola de fonoaudiologia na qual foi desenvolvido o estudo. Esta atende a população de uma cidade do interior do Estado deSão Paulo eestá dividida em setores, incluindo as áreas de linguagem, voz, surdez e neurologia. Além disso, a clínica oferece serviços de otorrinol aringologia, neurologia e audiologia.

Nos estudos desenvolvidos na perspectiva sócio-histórica, conforme apontado por Freitas (2003), procura-se, no processo de pesquisa, a oportunidade de reflexão e ressignificação do pesquisador e do pesquisado, uma vez que o pesquisador é considerado parte integrante da pesquisa, pois a sua compreensão dos fenômenos se constrói a partir do lugar que ocupa e das relações que estabel ece com os sujeitos os quais pesquisa. Assim, os dados obtidos durante a situação de interação entre os sujeitos permitirão também a compreensão do contexto social no qual eles emergem, permitindo que se estabeleçam relações entre eventos investigados, numa integração do individual com o social.

Segundo Wertsch (1998), é possível entender a relação entre o funcionamento mental humano e o contexto cultural, histórico e institucional, através da pesquisa desenvolvida sob o enfoque histórico-cultural.

Neste estudo, os sujeitos que compuseram o grupo de jovens com deficiência mental foram: Edson, Gilmar, Lúcia, Fernanda, Lucas, Daniel e Alex. ${ }^{4}$ Os jovens tinham entre 16 e 27 anos quando as reuniões foram realizadas e

\footnotetext{
${ }^{4}$ Vale ressaltar que os nomes verdadeiros dos sujeitos foram substituídos por fictícios, a fim de que fosse mantida a privacidade dos mesmos: Edson, 26 anos, deficiência mental leve, pertencente à família extremamente religiosa, há pouco tempo passou a assistir tel evisão e ouvir rádio, reside apenas com sua mãe, que possui perda auditiva moderadamente severa; Gilmar, 24 anos, Síndrome de Down, comunica-se basicamente por gestos, reside em um sítio com uma família adotiva; Lucia, 25 anos, deficiência mental moderada, única filha que reside com os pais, pertencente à família bastante religiosa; Fernanda, 16 anos, Síndrome de Down, mora com os pais e um dos irmãos, estuda em escola regular - classe especial; Lucas, 19 anos, Déficit de A tenção-Hipoatividade, reside com sua mãe e um irmão mais novo, embora tenha condições, não trabaIha, nem estuda, a família demonstra uma baixa expectativa em relação a ele; Daniel, 25 anos, Síndrome do X-frágil, mora com mãe, padrasto e uma irmã mais nova; Alex, 16 anos, Síndrome de Down, reside com sua mãe e seu irmão mais novo, freqüenta uma instituição de reabilitação.
} 
participavam semanal mente de atendimento fonoaudiológico, em grupo, com duas estagiárias do curso de fonoaudiologia.

O grupo dejovens foi filmado em vídeo durante os encontros semanais, realizados sem a criação denenhuma situação especial. A s reuniões, com estegrupo, já aconteciam a cerca de um ano quando iniciamos este estudo e, tinham como objetivo propiciar atividades interativas em diferentes situações discursivas. Levavam em conta a diversidade das configurações textuais (relatos, diálogos, comentários, recontagem, instruções etc.), ou seja, a tarefas de reformulação, modal ização e fortal ecimento dequadros interativos eesquemas de trocas verbais, favorecendo a diminuição de tensões emocionais e a partilha de experiências, evocando experiências sociais positivas, valorizando o interesse de um pelo outro eimpedindo o isolamento social, além de encorajar a necessidade de outras formas de comunicação ou possibilidades de significação que não apenas a lingüística.

Posteriormente, as fitas gravadas foram literalmente transcritas, o que permitiu a reconstrução dos diálogos, a descrição dos sujeitos e dos eventos ocorridos. Os dados analisados, neste estudo, referem-se às filmagens real izadas no período de dois anos.

Os dados foram anal isados segund o diretrizes da análisemicrogenética, conformepostulados da linha histórico-cultural, através do exame pormenorizado da fal a de cada participante, turno a turno, com o intuito de identificar os episódios nos quais os componentes do grupo manifestavam seus sentimentos a respeito da própria imagem edesuas histórias. Em seguida, esses episódios foram novamente analisados, com o propósito de identificar aspectos relevantes para o atendimento fonoaudiológico do deficiente, buscando transformações na auto-imagem, decorrentes da construção da linguagem no grupo terapêutico-fonoaudiológico.

Pautando-nos em Bakhtin (1988), procuramos examinar como se desenvolveram as argumentações de cada participante ao longo das interlocuções ocorridas nos encontros. Procurou-se determinar de que modo os vários discursos dos diferentes membros da reunião refletiram suas posições (lugares) sociais, eem que medida esta diferença influenciou os sentidos construídos.

\section{RESULTADOS}

Conforme descrito anteriormente, o presente estudo buscou refletir sobre a formação da identidade de jovens deficientes mentais que participam de atendimento fonoaudiológico, realizado em grupo, analisando o papel da linguagem nesse processo de construção da imagem queo sujeito faz desi mesmo.

A pós a leitura e releitura dos dados transcritos, foram levantados alguns temas, resultantes dos momentos da reunião nos quais ficaram mais explícitos os sentimentos relacionados à imagem que os sujeitos fazem de si mesmos. Vale ressaltar, que nem sempre o discurso dos jovens permitia uma 
identificação explícita da imagem queele estava fazendo desi, naquele momento. Mas o contexto no qual o discurso emergia e o olhar atento para os detal hes da interação que acontecia no grupo possibilitaram que se compreendesse e se relacionasse eventos singulares com o discurso circulante em nossa cultura, permitindo, dessa forma, direcionarmos nossa reflexão para o foco proposto neste estudo.

A seguir, apresentamos dois episódios que ocorreram em momentos distintos deatendimento no grupo terapêutico-fonoaudiológico, os quais permitem refletir sobre a imagem que esses sujeitos fazem de si.

\section{EpISÓdio 1:}

Os sujeitos discutiam sobre a preferência musical de cada um. A discussão teve início após a terapeuta, G, questionar o gosto musical de Lucas. Participavam da reunião, G e C (fonoaudiólogas/ terapeutas) e os jovens: Lucas (18 anos), Fernanda (16 anos), Lúcia (25 anos), Alex (16 anos), Gilson (24 anos) e Edson (26 anos).

1. Lucas - Gosto de Rap.

2. G - Você gosta de Rap? Verdade?

3. Lucas - (faz sinal positivo com a cabeça).

4. Fernanda - Eu também gosto de Rap.

5. G - Que grupo você gosta? (referindo-se, ainda, à Lucas).

6. Lucas - Um monte.

7. G - Um Monte. Meu irmão também gosta de rap, sabia?

8. Lúcia - Eu gosto só hino.

9. G - Você gosta de hino?

10. Lúcia - Gosto, você não gosta?

11. G - Eu gosto, eu acho bonito. Você não acha bonito o que eles falam no hino? (referindo-se à Lúcia).

12. Fernanda - Eu gosto. A Damara, a minha colega, gosta do hino.

13. G - Verdade!? Como é que é o hino?

14. Fernanda - (levanta os ombros, referindo não saber).

15. G - Não lembra? Que hino você gosta, Lúcia?

16. Fernanda - (fala ininteligível, ao mesmo tempo em que a terapeuta faz a pergunta para Lúcia).

17. Lúcia - Cassiane.

18. G - Quê?

19. Lúcia - Cassiane.

20. G - Cassiane? É uma cantora?

21. Lúcia - Ela é.

22. C - Como que chama, Lu?

23. Lúcia - Cassiane.

24. C - Cassiane?

25. Lúcia - (faz gesto afirmativo com a cabeça).

26. G - E você, Alex? Você gosta de algum cantor, alguma música? 
27. Alex - (faz gesto afirmativo com a cabeça).

28. G - De quem você gosta?

29. Alex - Da Xuxa.

30. G -De quê??

31. Alex - Da Xuxa.

32. G - Da Xuxa? Ah, que legal, quem mais?

33. Alex - (Não responde).

34. C - E você, Edson, você ouve música?

35. Edson - Não.

\section{EpIsódio 2:}

N um outro encontro, participavam da reunião, G eC (fonoaudiólogas/ terapeutas) e os jovens: Lucas (18 anos), Fernanda ( 16 anos), Lúcia (25 anos), Alex (16 anos), Daniel (23 anos) Gilson (24 anos) e Edson (26 anos). As terapeutas retomam o assunto sobre a preferência musical dos sujeitos.

1. C - Que tipo de música você gosta?

2. Edson - Da Xuxa (sorrindo).

3. C - Da Xuxa, ele gosta da música da Xuxa (falando com Daniel).

4. G - E você, Lúcia?

5. Lúcia - Eu gosto... (inaudível).

6. G - Rock? E você, Alex?

7. Alex - Daniel.

8. G - Daniel! Daniel é bom!

9. Edson - (dá risada e bate na mesa).

10. C - E você, Gilson? Que música você gosta?

11. Gilson - (estica uma das mãos, e com o dedo indicador da outra mão faz um círculo em sua mão esticada).

12. Fernanda - Ele que rock.

13. C - O que é isso?

14. Gilson - (continua fazendo o movimento com as mãos).

15. G - É o disco?

16. Gilson - (com uma mão faz como se estivesse pegando algo, como uma pinça).

17. C - Você comprou também?

18. (Fernanda) (faz gesto afirmativo com a cabeça).

19. G - Eu vi o seu CD. Como que chamava mesmo? Você mostrou o CD que você comprou, é de uma dupla sertaneja!

20. Gilson - (verbaliza e aponta para cima)

21. G - É de uma dupla sertaneja, né!

22. C - E você Fernanda, que música você gosta?

23. Fernanda - Zezé di Camargo e Luciano (dando risada e deitando a cabeça sobre a mesa)

24. Daniel - começa a música e Fernanda, logo em seguida, acompanha-o) "Minhoca, minhoca, me dá uma beijoca, não dô..."

25. C - Mas essa música é de criança, canta outra que você gosta.

26. Fernanda - Eu gosto di...(fala inaudível). 


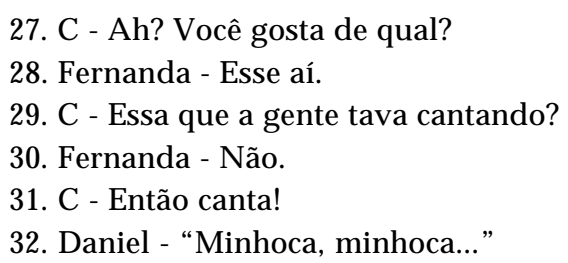

Nestes dois episódios, podemos observar a postura infantil quealguns sujeitos assumem ao revelarem as suas preferências musicais. Alex, no primeiro episódio, diz que gosta da Xuxa. Edson, então com 26 anos de idade, também afirma, no segundo episódio, gostar da Xuxa. Fernanda e Daniel, ao serem questionados sobre as suas preferências musicais, começam a cantar uma música típica de criança: "M inhoca, minhoca...". Os sujeitos revelam ora ocupar o lugar dejovens, quando alguns manifestam gostar de músicas ouvidas eapreciadas por jovens de seus grupos sociais (Rap e Hinos religiosos), ora assumem a posição de crianças, quando outros indicam preferência por um estilo de música bastante infantil, que, provavelmente, não seria um estilo apreciado pelos outros jovens de mesma idade. Fica explícita, assim, a imagem não clara que os jovens fazem desi. Entretanto, esta imagem não éformada independentemente do grupo social, mas construída socialmente por este grupo.

Conforme apontado por Góes (2004), aquilo que os sujeitos revelam em seus discursos é o resultado do modo como eles assimilam em suas próprias falas os dizeres das diferentes vozes do grupo social. Os enunciados produzidos pelo grupo são incorporados evão compor a imagem quefazem de si. Isto significa dizer que a constituição do sujeito se dá pela linguagem, através de um processo essencialmente dialógico, que procede das e ocorre nas interações sociais. $\mathrm{Nas}$ pal avras de Bakhtin:

O sujeito é constituído por diversas vozes - polifonia. Quando se expressa, usa uma linguagem que não ésó dele, étambém de outros. O fato de ser constituído por muitas vozes concorre para a heterogeneidade do sujeito. Essa heterogeneidade provém da constituição do "eu" e do "outro", o outro que é constituído, também, por muitas vozes, numa cadeia infinita de "outros". (BAKHTIN, 1997, p. 314).

Um terceiro episódio torna mais clara a relação entreas vozes do grupo e os dizeres do sujeito deficiente. Nele vemos as duas terapeutas, que ali representam o grupo social, revelando uma expectativa bastante infantil em relação ao sujeito deficiente.

\section{EpIsódio 3:}

Neste episódio, participavam da reunião, G e C (fonoaudiólogas/ terapeutas) e os jovens: Lucas (18 anos), Fernanda (16 anos), Lúcia (25 anos), A lex 
(16 anos), Gilson (24 anos) eEdson (26anos). O grupo está conversando sobre suas preferências. A discussão tem início após uma das terapeutas perguntar a um dos sujeitos sobre a sua preferência.

1. G - O que você mais gosta de fazer, Fernanda?

2. Fernanda - Tudo!

3. G - Tudo. Mas o que você mais gosta de brincar, de fazer?

4. Fernanda - Brincar, de assistir televisão e várias coisas!

5. G - Ah, e você, Lucas?

6. Lucas - Fala ininteligível.

7. G - N ossa, élegal, mas eu não sei jogar muito bem e o que mais?

8. Lucas - Só.

9. G - E você, Edson, o que mais gosta de fazer?

10. Edson - (está concentrado, fol heando uma revista, por isso nada responde).

11. G - Oh, agora a gente tá conversando.

12. Edson - (permanece olhando para a revista).

13. G - Você gosta de recortar?

14. Edson - (faz gesto afirmativo com a cabeça).

15. G - Que mais?

16. Edson - (faz gesto negativo com a cabeça).

17. G - Só? E você, Gilson?

18. Gilson - (não responde)

19. G - Você gosta de andar a cavalo, né?

20. Gilson - (faz gesto afirmativo com a cabeça).

21. G - Que mais?

22. Fernanda - Eu também gosto de andar de cavalo.

23. G - Oi?

24. Fernanda - Eu também gosto de andar de cavalo.

25. G - Você também gosta? E vocês também gostam? (referindo-se a Lucas e Edson).

26. Fernanda - Ele faz assim: "Segura peão!"

27. G - É assim que faz, Gilson?

28. Gilson - (faz gesto afirmativo com a cabeça).

Na tentativa de obter uma resposta mais específica, a terapeuta tenta explicar melhor a sua pergunta (turno 187) e acaba revelando uma expectativa infantil em relação ao sujeito deficiente. Vemos a própria terapeuta perguntando a uma jovem de 20 anos: "M as o que vocêmais gosta de brincar, de fazer?" Estepequeno detal he não só revela a imagem que o terapeuta tem do sujeito, mas colabora para incentivar a conversa nessa direção.

Segundo Kassar (2000), a constituição da subjetividade do indivíduo é marcada pelas condições materiais eideológicas nas quais o indivíduo seinsere. A capacidade de significar (dar sentido a, interpretar e fazer-se entender) de cada indivíduo passa a existir pelos significados atribuídos pelos outros às suas ações. O "significar do outro" está na gênese do comportamento "significativo" do "eu", na gênese do pensamento de cada indivíduo, que vai constituindo-se inserido em 
um mundo simbólico/ lingüístico, onde a linguagem possibilita a constituição/ organização do pensamento.

\section{Discussões E CONCLUSÕ̃S}

Kassar (2000) afirma que, assim como os demais conceitos e val ores, o modo como as pessoas significam sua existência também acontece socialmente, na tensão entre diferentes vozes, queaos poucos vão encontrando ou não ressonância no indivíduo.

No discurso dos jovens que participaram deste estudo, pudemos observar uma imagem de si mesmo reveladora dos valores e imagens atribuídos pela sociedadea sujeitos deficientes mentais. A imagem infantil queos jovens têm de si mesmos reflete o discurso do grupo social que está a sua volta. A própria terapeuta, quando pergunta ao jovem do que ele gosta de brincar, deixa escapar em seu discurso a visão infantil que tem do mesmo.

A transformação ou não da imagem que os sujeitos deficientes mentais fazem de si mesmos permitenos avaliar o quanto a clínica pode colaborar ou não para o desenvolvimento da linguagem e para a constituição de cidadãos.

Concordamos com Manfezolli (2004) quanto à constituição restrita possibilitada pelo grupo social aos sujeitos deficientes mentais e quanto

[...] à necessidade de uma efetiva mudança na maneira de ol har para esses jovens e adultos, a necessidade da promoção de práticas realmente significativas para que eles possam identificar-se como tais, com direitos e deveres de cidadãos numa sociedade democrática, que diz oferecer oportunidades de desenvolvimento e autonomia para todos. (MANFEZOLLI, 2004, p. 95)

Para conseguirmos obter as mudanças necessárias e transformar a imagem que os sujeitos deficientes mentais têm de si mesmos, precisamos ações que incidam sobre aqueles que os rodeiam, ou seja, a família, os amigos, os col egas eo grupo social em geral. É urgente quetais ações sejam iniciadas eque considerem a natureza do processo, muitas vezes lento e difícil, para conquistar mudanças nos valores e práticas sociais.

Precisamos levar tais reflexões para os cursos de formação dos profissionais queatuarão junto a esses sujeitos esuas famílias. A través da mudança nos ol hares de educadores e clínicos podemos transformar, ainda quelentamente, a imagem que o grupo social tem dos deficientes mentais e, assim, garantir os direitos destes em nossa sociedade. 


\section{Referências Bibliográficas}

BAKHTIN, M. M arxismo eFilosofia da Linguagem. 4.ed. São Paulo: Hucitec, 1988. . Estética da criação verbal. São Paulo: Martins Fontes, 1997.

ERIKSON, E. H. Identidade, juventude e crise. Rio de Janeiro: Zahar, 1972.

FREITAS, M.T. deA. A perspectiva sócio-histórica: uma visão humana da construção do conhecimento. In: FREITAS, M. T. A. et al. Ciências H umanas e P esquisa: leituras de Mikhail Bakhtin. São Paulo: Cortez, 2003. p. 26-38.

FROM M , E. Consciência esociedadeindustrial. In: MARTINS, J. S. et al. Sociol ogia esociedade. São Paulo: 1977.

GLAT, R. Somos iguais a vocês: depoimentos de mulheres com deficiência mental. Rio de janeiro: Editora A GIR, 1989.

GOES, M. C. R. de. Desafios da inclusão deal unos especiais: a escolarização do aprendiz e sua constituição como pessoa. In: GÓES, M. C. R.; LA PLANE, A. L. F. (Org.). Políticas e práticas da educação inclusiva. Campinas: Autores A ssociados, 2004. p. 69-91.

GOFFMAN, E. Estigma: notas sobrea manipulação da identidadedeteriorada. Rio deJaneiro: Zahar Editores, 1982.

KASSAR, M. C. M. Marcas da história social no discurso de um sujeito: uma contribuição para a discussão a respeito da constituição social da pessoa com deficiência. Cad. Cedes, v.20, n.50, p.41-54, 2000.

KIM MEL, D.C.; WEIN ER, I . La adolescencia: una transición del desarrollo. Barcelona: A riel, 1998.

LIMA, R. P; MAIA, R.; DISTLER, S. D. Reflexão sobre um trabalho com famílias. Espaço, V.11, p. 37-39, 1999.

LOPES, J. R. Os caminhos da identidade nas ciências sociais e suas metamorfoses na Psicologia Social. Psicologia Social. v.14. n.1. p.7-27, 2002.

MANFEZOLLI, R. R. O Iha eu já cresci: a infantilização dejovens eadultos com deficiência mental. 2004. Dissertação (M estrado em Educação)-Universi dade M etodista de Piracicaba, Programa de Pós-Graduação em Educação, Piracicaba, 2004.

SILVARES, E. F. M.; SHOEN-FERREIRA, T. H; AZN AR-FARIAS, M. A construção da identidadeem adolescentes: um estudo exploratório. Estudos em P sicologia, $N$ atal, v.8, n.1, p. 107-115, 2003.

WERTSCH, J. V. A necessidade da ação na pesquisa sociocultural. In: WERTSCH, J. V.; RIO, P.; ALVA REZ, A . Estudos Socioculturais da mente. Porto Alegre: Editora Artes Médicas Sul Ltda, 1998. p.56-71.

Recebido em 05/ 10/ 2007

Reformulado em 25/ 03/ 2008

A provado em 16/ 08/ 2008 